E.L.U.A., 6, 1990, pp: 89-106.

\title{
EL TEXTO, LUGAR DE ENCUENTRO DE LA SEMIÓTICA
}

\author{
J. ALBERT GALERA \\ (Universidad de Barcelona)
}

0 . El lenguaje, como lugar de encuentro entre el ser humano y la realidad, constituye el fundamento de las relaciones humanas, erigiéndose así en pieza básica de intercambio de ideas. En efecto, la comunicación lingüística se puede considerar como la producción de un enunciado que parte de un sujeto hablante con destino a otro sujeto hablante, respetando ciertas categorías o máximas que componen el principio de cooperación, como fundamento de la conducta lingüística. Es decir que, en toda comunicación mediante signos lingüísticos, sea gráfica o fónica la sustancia de la expresión utilizada, subyace el modelo clásico de comunicación, en el que existen varios roles, entre los a que se cuentan el emisor y el receptor, que son los dos roles más importantes, y la secuencia de sonidos, tercero de los roles. El canal de comunicación es el que posibilita el transporte de los signos del hablante al oyente. Claro que, como se verá, no pretendo con el esquema esbozado presentar la totalidad real de la comunicación discursiva (Bajtin, 1982: 257-258).

1. La existencia de un mensaje implica que es «significativo» para el emisor e «informativo» para el receptor o destinatario, aún en el caso de que se tratara de recordar simplemente algo ya conocido. Sabido es que toda información puede llegar a un buen número de receptores, pero sólo está destinada a uno en concreto, con el que se acopla el emisor y cuya cultura, disposición, necesidad, etc. debe conocer si pretende influir en el receptor o conseguir alguna cosa de él. Así, el uso del lenguaje activa una serie de conocimientos que las palabras evocan y que no necesitan hacer explícitas (Reyes, 1990: 53). Esto ocurre siempre que la comunicación es intencional.

La idea de que cualquier manifestación idiomática tiene como fin provocar una reacción en el interlocutor, implica el reconocimiento de una unidad superior, formada por todas las interiorizaciones que sirven para probar, en una 
determinada situación, una reacción del interlocutor, incluso si éste, que ha oído y entendido, no reacciona - no dar respuesta es también una respuesta- 1 . Un rasgo del lenguaje es su carácter activo: la tendencia que impulsa la palabra a servir a la acción (Bally, 1977: 25).

$\mathrm{Si}$, en efecto, ha habido entendimiento, quiere decir que al principio y al final de la acción de hablar/oír o escribir/leer hay un saber, una conciencia: el hablante sabe lo que quiere y el oyente sabe lo que se quiere decir (Porzig, 1974: 179).

2. El funcionamiento del lenguaje en el que, en cierta manera, todo nuestro cuerpo está metido en tanto que se refiere a las situaciones reales en las que lo usamos, creándolo, a la vez que nos va creando, plantea toda una serie de interrogantes como las siguientes: ¿Qué factores han intervenido y cómo se han combinado para que se produzca efectivamente una comunicación lingüística? $\mathrm{O}$, lo que es lo mismo, ¿qué ha sucedido en la mente del emisor hasta llegar a disponer de una estructura lingüística dispuesta para ser transmitida a través de un canal y qué ha sucedido a su vez en la mente del receptor para comprender el mensaje encerrado en dicha estructura lingüística?

La respuesta a los interrogante anteriores exige, en una teoría de la interpretación de la realidad lingüística, que se estudie el lenguaje en función de la comunicación, es decir, que se ocupe de la relación entre el lenguaje y el hablante para averiguar cómo se comprenden, almacenan, reproducen y producen los enunciados o, mejor dicho, los textos (Van Dijk, 1983: 20-21).

Toda una serie de procesos interiorizados, de los que apenas podemos saber algo por observación directa de los interlocutores, se dan entre hablante y oyente.

La propia experiencia nos enseña que una vez que nos hemos puesto en contacto con los asuntos, la expresión surge de una manera «espontánea» como si se tratara de un automatismo a lo viejo catón: «Ren tene, verba sequentur», 1o que quiere decir que los aspectos psicológicos desempeñan un papel fundamental en la elaboración y comprensión de los textos.

Desde el momento en que percibimos las señales a través de los sentidos, se desencadenan en el cerebro una serie de procesos, que ponen a prueba nuestra capacidad para aislar las unidades discretas de un enunciado, realizando un proceso de abstracción, donde esas mismas unidades se combinan, respondiendo a unos principios y conectando, al mismo tiempo, con conocimientos anteriores, donde la memoria a largo plazo («long term memory») y corto plazo («short term memory»), juega un papel fundamental (Van Dijk, 1983: 6.2.). Todo este proceso dará como resultado el texto objeto de la comunicación.

3. Distinguimos entre enunciado o discurso y texto. El primero tiene que ver con lo que Weinrich denomina «texto», es decir, cualquier libro en la medida

«El silencio también produce significado, porque es un hecho lingüístico, en la medida en que consiste en no decir - omitir, ocultar - o en dar algo por ya dicho - dar a entender, presuponer(...). La pragmática estudia el silencio que comunica algo volutnariamente». (Reyes, 1990: 18). 
en que se distingue de otro, así como cada una de las partes de ese mismo libro que están separadas por espacios intermedios y llevan epígrafes (Weinrich, 1981: 52-54). Se entiende como la manifestación terminal-lineal, es decir, como observable (Albaladejo-García Berrio, 1983: 221).

El texto, por el contrario, es un tipo de producción significativa que no es pensable más que en la materia lingüística. Es el engendramiento de la significación estructurada, cuya operación (linguística) desemboca en el denominado por Julia Kristeva feno-texto (1978: 95-217). En este sentido puede decirse que el texto es productividad (Kristeva, 1874: 15ss.) y debe ser considerado como un objeto dinámico, que, en último término, depende de la intención comunicativa del hablante. Es, en definitiva, lo que hay detrás de un discurso, que, para ser tal, debe cumplir unas determinadas condiciones (AlbaladejoGarcía Berrio, 1983: 221-233).

El texto no es, por lo tanto, un conjunto de enunciados gramaticales, sino la lectura de un «alfabeto de unidades sometidas a una dinámica interna concreta». Es una práctica compleja cuyos símbolos gráficos deben ser aprehendidos por un acto significativo específico, trascendiendo los propios grafemas, aunque sin romper la atadura con el plano ejecutado, que es el que genera la lectura adecuada (Ramón Trives, 1979: 185-187).

4. Para la investigación de la estructura interna del discurso existen varios caminos. Se puede dirigir la atención a la manifestación externa, evitando partir de la significación de los diferentes miembros. En este caso puede utilizarse un método estructural que, como tal, prescinde conscientemente de las relaciones vitales del hablar mismo y de los participantes en ese hablar. $\mathrm{Si}$, por el contrario, deseamos poner a los interlocutores en el centro del análisis, investigando el comportamiento recíproco de los hablantes en su relación con la expresión, será el behaviorismo el método apropiacio. También en el análisis de textos se puede atender a la relación de la expresión con el estado de cosas. Es decir, se puede utilizar una gramática aplicada que trate de averiguar qué contenidos quieren significarse con una expresión determinada, partiendo del supuesto de que, en muchos casos, la estructuración de la realidad no está de acuerdo con la expresión que se refiere a ella (Porzig, 1974: 96-175).

Todos estos métodos se consideran científicos por sus seguidores porque creen haber descubierto la «realidad del lenguaje», la clave que permite describir y explicar cualquier texto. Pero «no hay un único texto a explicar, sino varios objetos de explicación diferentes que requieren diferentes dispositivos explicativos» (Rieser, 1978: 45). De ahí que no se pueda o no se deba hablar de una única metodología. «El texto - señala García Berrio- como plano de la consideración de la lengua y como unidad-entidad concreta del discurso lingüístico, asume, organiza y relaciona la perspectiva/nivel pragmático con los integrantes linguísticos (1979: 147). Un estudio integrado en el análisis del texto deberá describir y explicar las relaciones internas y externas de los distintos aspectos de las formas de comunicación y uso de la lengua (Van Dijk, 1983: 9-11; Reyes, 1990: 17-20), sin olvidar la relación de la lengua con el 
hombre, lo que impide separar el lenguaje como estructura pura de los componentes de la comunicación y de las metas del hablante. A este respecto, ya en 1943 Hjelmslev decía:

«La teoría lingüística se inclina por necesidad interior a reconocer no solamente el sistema lingǘstico, en su esquema y en su uso, en su totalidad y en su individualidad, sino también al hombre y a la sociedad humana que hay tras el lenguaje. Y entonces alcanza la teoría linguística la meta que se ha prescrito: humanitas et universitas» (p. 176).

Deben, por tanto, ser integrados todos los procedimientos en la tarea de desentrañar, interpretar y explicar un texto (Albert, 1987:9), y sólo en este caso será posible comprender y hasta construir cualquier texto de lengua natural.

5. Lo dicho hasta este momento constituye un metalenguaje, que trata de explicitar las condiciones extratextuales de la aprensión y de la producción del significado de un texto. Se trata de una «visión de conjunto de todos los elementos que intervienen en el uso de los signos, de donde puede proceder de algún modo de sentido»(Bobes Naves, 1989: 97), es decir, de la pragmática.

Claro que para el estudio textual hay que contar con otros niveles, como es la relación de los signos entre sí y de éstos con los denotata, al estilo de Morris, en su conocida contribución a la International of Unified Sciencie, titulado Foundations of Theory Signs (Chicago, 1938), en la que afirma que una lengua puede ser caracterizada de un modo exhaustivo, diciendo que es un conjunto de reglas sintácticas, semánticas y pragmáticas (1958: 35). Más tarde Brekle asegurará que «une langue (dans l'acception sémiotique compläte du mot) est une ensemble intersubjectif de signifiants, dont l'emploi est regi par des rägles syntaxiques, sémantiques et pragmatiques» (1974: 33). El Prof. Ramón Trives lo resume así: «Lo que digo - semántica-, que no es independiente de cómo lo digo - sintaxis- (...), está en función de lo que quiero u objeto de mi decir —pragmática- (...)» (1980: 19).

De esta manera llegamos a la semiótica como teoría aplicada a la investigación lingüístico-literaria, que se sitúa en la tradición saussureana (Saussure, 1976: $60)$.

6. La semiótica trata de elaborar los procedimientos descriptivos, presentado un modelo, que no es otra cosa que una hipótesis, resultado de la intuición del sujeto del hacer científico (Greimas-Courtes, 1982; Kristeva, 1978: 35-52). No se olvide que la intuición, aunque es personal frente a la ciencia que requiere que sus métodos y resultados sean públicos, es un componente de la competencia cognoscitiva (Robins, 1976: 28-29), es decir, forma parte del bagaje científico $y$, en la medida en que vaya siendo sustituida por el modelo propuesto, si éste es válido, se convertirá en ciencia. Los componentes procesales de que habla Albaladejo tienen que ver con lo dicho aquí sobre la intuición (1983). 
Se ha insistido repetidamente en la importancia de la pragmática ${ }^{2}$ intérpretes» (1962: 207). Según esto lo que importa, por ejemplo, en un acto de comunicación, juntamente con la secuencia de signos, es la manera de actuar del emisor para que el destinatario del mensaje lo capte en su totalidad y actúe en consecuencia, porque todo en el lenguaje lleva la huella pragmática (Ramón Trives, 1980: 1320). Sin embargo, el enunciado comunicativo debe ser especificado desde diferentes perspectivas. «Ningún texto debe reducirse a la dimensión discursiva meramente expresable, sino que se extiende a dominios de presuposiciones, de incorporaciones referenciales, etc» (García Berrio, 1979: 147). Por un lado, los signos funcionan como tales en virtud de su agrupamiento en la cadena sintagmática (relaciones «in praesentia»), cuyo valor se completa con otro tipo de relaciones con las que se cruza, las paradigmáticas o relaciones «in absentia» (Saussure, 1976: 206ss.). Se trata de especificar el resultado de la actividad verbal partiendo de ( $y$ atendiendo únicamente, en una primera fase a) las estructuras desarrolladas o cotexto ${ }^{3}$. La cotextualidad opera con sus propias informaciones internas precindiendo del entorno en el que ha sido engendrado el texto. Se opera a este respecto con la representación semántico-intensional.

Por otro lado, la existencia del aspecto contextual (Van Dijk, 1980: 270274) significa que la interpretación de un texto tiene su fundamento en una semántica extensional, lo que implica que las condiciones necesarias y suficientes para el funcionamiento de la semántica son en parte de naturaleza combinatoria y establecidas por encadenamientos lógicos. El aspecto contextual tiene que ver con la estructura del mundo que emerge del discurso y con ella «se intenta dar cuenta del objeto lingüístico, de la estructura comunicativa en la que dicho objeto se encuentra inserto ${ }^{4}$.

2 Véase Levinson, Stephen C.: Pragmatics (1983), traducción castellana en la Editorial Teide con el título de Pragmática (1989) y la bibliografía que aporta sobre el tema. También, Graciela Reyes: La pragmática lingüística (1990), Madrid, Editorial Montesinos.

${ }^{3}$ Petöfí, 1975: 1 y 8-9. El mismo autor opina así sobre la pragmática: «La pragmatique traite des relations entre les expressions, les objets auxquels elles réfèrent et les usagers ou les contextes d'usage des expressions» (pp: 89). Véase también a este respecto, Schmidt, 1977: 41-50. Brekle (1974) añade: «La tâche de la pragmatique est de rechercher quelles sont les conditions de productions des actes de parole. A ses conditions appartient en tout premier lieu la satisfaction des critères de bonne formation syntaxique et sémantique; mais, il faut y ajouter un large ensemble de facteurs et de conditions que sont nécessaires à la formation d'actes de parole et qui, sous certaines conditions à définir, sont des éléments déterminants d'un procès de communications réussi». (pp: 78).

${ }_{4} \ll$ a) in primo luogo abbiamo la struttura comunicativa esterna della comunicazione nella quale si trova inserito el testo che è comunicato. Tale struttura è costituita dalle seguenti variabili: emissore e recettore, testo di lingua oggetto e contesto di comunicazione che si sdoppia in contesto di emissione e contesto di recezione. Questa struttura comunicativa è di tipo pragmatico ed è situata in una dimensione contestuale. La struttura comunicativa esterna esiste per tutti i testi;

b) in secondo luogo abbiamo la struttura comunicativa interna dell'enunciato che si presenta in quei testi in cui è raccolto un atto comunicativo, come avviene nei testi di dialogo. Tale struttura soggiace all'atto o agli atti comunicativi che sono testualizzati in quei testi. Le variabili che formano questa struttura sono: emissore e ricettore partecipanti all'atto o atti di comunicazione testualizzati nell'enunziato, espressioni o testi comunicati in tali atti e contesto o contesti di comunicazione che si sdoppiano in contesto o contesti di emissione e in contesto o contesti di recezione. La struttura comunicativa interna è in primo luogo di carattere semantico-intensionale 
7. El estudio de los aspectos cotextuales y contextuales abarca la totalidad del texto, que es lo que la pragmática lingüística tiene como objeto de estudio, es decir, «las relaciones que existen entre las expresiones de lengua natural, los participantes en el proceso comunicativo y el contexto de comunicación» (Albaladejo, 1983: 4).

El texto, pues, es el resultado de la interacción dinámica entre el conocimiento del mundo que tiene el hablante y las dimensiones sintáctico-semánticas del enunciado. Porque el lenguaje solamente puede ser explicado con el sistema de un contexto de comunicación y éste sólo puede ser explicado a través de una teoría integrada de sintaxis, semántica y pragmática (Oller, 1972: 43-55). Esta es la propuesta de Albaladejo que suscribimos: «es posible y adecuada la elaboración de un componente pragmático que, envolviendo el componente de gramática textual, el de semántica del mundo y el de léxico del modelo lingüístico-textual, recoja de modo explícito todos los aspectos del lenguaje y constituya un modelo de comunicación lingüística juntamente con el resto de los componentes que están englobados en él» (1983: 6; Van Dijk, 1983).

8. De lo dicho hasta aquí, pueden extraerse una serie de componentes que, integrados en un modelo, permitan estudiar cualquier texto de lengua natural.

8.1. El nivel cotextual tiene como objeto la búsqueda del significado que emerge de los propios signos y de las relaciones establecidas entre oraciones y expresiones que forman el entramado de la manifestación textual. El estudio de la obra en sí llevará necesariamente a buscar la conexión de cada elemento del texto con todos los demás presentes en él, pues la concreción de cualquiera de las posibilidades significativas del signo lingüístico se realiza en la combinación y relación con otros signos, operación que desemboca en la producción del discurso.

Los conceptos de 'coherencia' y 'conexión' se encargarán de ir justificando las relaciones que dan lugar al texto. La coherencia tiene que ver con las relaciones especificativas entre frases (Van Dijk, 1980: 81), es decir, con la conexión entre proposiciones, que viene determinada por las relaciones entre los hechos denotados por ellos en mundos relacionados (Albert, 1989). También por la identidad del referente a la que remiten varias oraciones de la secuencia (Van Dijk, 1983: 47). La presencia de nuevos referentes puede introducirse mediante una relación implícita o directamente expresada con referentes introducidos anteriormente. El texto así obtenido y justificado mediante conexión lineal es un texto que posee coherencia lineal y así lo percibe el receptor lingüista ${ }^{5}$

\footnotetext{
per quanto riguarda la dimensione contestuale a cui appartiene, in secondo luogo è di tipo pragmatico per la sua propria condizione comunicativa, benché interiore al testo». (Albaladejo, 1982: 114).

${ }^{5}$ «El productor común es aquel que produce un texto de lengua natural teniendo como finalidad la comunicación del mismo a un receptor; el productor lingüista es el que en su producción de un texto de lengua natural tiene como finalidad el estudio de éste y de su comunicación, representando formalmente los procesos que en él, como productor común, tiene lugar, así como los elementos, las construcciones concretas que él, como productor común obtiene; para todo ello se sirve el productor lingüista de un instrumental teórico». (Albaladejo, 1983: 11).
} 
La coherencia puede ser también global, es decir, puede brotar del mismo enunciado considerado en su totalidad y no de las conexiones entre oraciones aisladas. Quiere ello decir que puede hablarse de un concepto, que organiza jerárquicamente la estructura conceptual de la secuencia, que viene a ser la manifestación superficial de la macro-estructura; es el tópico del discurso que funciona como una representación abstracta de la estructura global del significado de un texto. Por ejemplo, la coherencia justifica la sinopsis que un hablante/ lector realiza de un texto emitido/recibido.

Las macro-estructuras se obtienen aplicando un número de operaciones que tienen por objeto reducir la información semántica, subsumiendo así un cierto número de proposiciones. También las macro-estructuras determinan la conexión lineal y la coherencia de las secuencias (Albert, 1987: II.1.1.1. y III.7.).

El papel que juegan las macro-estructuras en la producción y comprensión del discurso tiene que ver con la información semántica almacenada en la memoria. Lo que realmente se almacena en ella es la macro-estructura del discurso. Por eso cuando un sujeto reproduce un relato, produce un discurso que contiene principalmente macro-proposiciones. La producción y recepción de textos supone la existencia de un plan global subyacente a las series de representaciones semánticas (Van Dijk, 1980: 234). El plan coordina el decurso de tales acciones particulares con vistas a un determinado resultado final que ha de lograrse (Van Dijk, 1983: 87). Es decir, dispone las reglas, convenciones y estrategias para la producción verbal o, lo que es lo mismo, como manifestación de una enunciación-en-función: la presencia de textualidad socio-comunicativa realizada. La textualidad es el modo de manifestación universal y social que se usa en todos los lugares para la realización de la comunicación (Schmidt, 1973: $135)$.

Cuando Porzig dice que la «ordenación de las palabras en la frase no se deja en ninguna lengua al arbitrio» (1974: 154), está hablando de un componente gramatical esencial en la construcción de un texto. Podríamos denominarlo «componente de buena formación sintáctica» (FS). Este operador se encarga de la formación correcta de las frases, y uno de sus cometidos es rechazar frases como la siguiente:

\section{a) *Artículo ahora redactando un estoy,}

que resulta un sinsentido y que al reconstruirla, ordenando correctamente sus elementos, recupera el sentido. Así, tendríamos;

\section{b) Ahora estoy redactando un artículo.}

La misión subsidiaria de este componente consiste en procurar la apropiada combinación de las palabras en la frase delimitando el campo sintáctico (Porzig, 1974: 133).

Normalmente el receptor lingüista no recibe textos de estructura similar a a). De la buena formación sintáctica ya se ocupa el emisor lingüista. El FS puede además transformar una frase negativa en afirmativa, si ello facilita el análisis del texto (Albert, 1987: II.1.1.).

Debe hablarse también de un componente del léxico (CL), cuyo cometido 
será la selección de los signos lingüísticos adecuados a la representación dentro del inventario de que dispone el autor de un texto. Este parámetro se encarga de explicar por qué un determinado constructo incluye ciertas piezas léxicas para expresar un sentido concreto. Piezas léxicas que, por otra parte, manifiestan una cierta organización de la realidad. No se olvide que las unidades de la lengua están organizadas y agrupadas por campos formados por miembros ordenados contigua y consecuentemente. Son los campos paratácticos de que nos habla Porzig (1974: 128).

Para la producción y recepción de tex tos semánticamente coherentes también es necesario el establecimiento de un marco, como estructura conceptual en la memoria semántica que organiza el conocimiento convencional de la situación concreta. Cumple la función de integrar las partes de un todo, justificando y orientando las diferentes operaciones que conducen precisamente a lograr el objetivo de la comunicación textual. La interpretación de determinadas situaciones y comportamientos tiene precisamente su razón de ser en el conocimiento del marco. Así, por ejemplo, el marco de «explicación de una lección» indica las acciones que deberán llevarse a cabo y en qué orden, para conseguir que los estudiantes aprendan los contenidos esenciales de dicha lección, en la hipótesis de que ese sea el objetivo. El conocimiento del marco obligará a leer sobre el tema de la lección que se va a explicar, caso de que no se conozca suficientemente. Incluso conllevará otros actividades como hacer una síntesis de las lecturas realizadas y, si es pertinente, preparar un guión del tema. Pero, además, el sujeto que debe explicar la lección tendrá que desplazarse hasta el lugar dónde deba encontrarse con los alumnos y hablarles del tema en cuestión. Para asegurarse de que ha conseguido el objetivo propuesto deberá adoptar la estrategia adecuada a tal fin, es decir, podrá dialogar con ellos sobre el tema o proponerles algunas cuestiones, cuya resolución tenga que ver con la asimilación de lo explicado.

Son todas ellas acciones coherentes con el marco, que constituyen la expansión y el desarrollo de la macro-estructura de la lección o el texto.

8.2. La segunda de las dimensiones, que para el estudio del texto debe abordarse es el aspecto contextual. Entre los parámetros contextuales, no solamente son importantes las huellas que los comunicantes han dejado en el texto, sino además las relaciones lingüistico-comunicativas que se dan entre ellos y con el mensaje propiamente dicho (Albaladejo-García Berrio, 1983: 219). No debe olvidarse, a este respecto, que la actividad lingüistica humana es de naturaleza esencialmente social y cultural y, precisamente por ello, las intervenciones de los hablantes/autores de los textos funcionan dentro de un marco restrictivo (Bustos, 1986:12), condicionando, de esta manera, la aceptabilidad de las expresiones lingüísticas ${ }^{6}$.

\footnotetext{
'García Berrio-Albaladejo, 1983: 127-129; Albaladejo, 1981: 139; Austin opina sobre este tema así: «Desde hace años venimos advirtiendo cada vez con mayor claridad que la ocasión en que una expresión se emite tiene gran importancia, y que las palabras usadas tienen que ser «explicadas», en alguna medida, por el «contexto» dentro del cual se intenta usarlas o fueron realmente usadas en un intercambio» (pp: 114).
} 
La presencia en el texto de un «yo» que se dirige a un «tú» compromete al hablante/escritor imprimiendo al mensaje una mayor fuerza persuasoria. El papel que desempeñan los interlocutores en el momento del enunciado (implicaturas convencionales para Grice (Levinson, 1989: 117-122)), el intercambio entre el sistema de valores del autor y del oyente/lector, así como el uso de reglas regulativas del comportamiento linguístico, que tiene que ver con el principio de cooperación ${ }^{7}$ y otros factores que hacen posible la comunicación, no es indiferente a la hora de lograr actos de comunicación eficaces (Schmidt, 1973: 5.4.1.1.). Sabido es que una oración podría contradecirse en contextos especificativos de comunicación distintos, mediante proposiciones que forman parte del conocimiento acumulado del hablante y del oyente, así como de la posición que cada uno ocupa con respecto al otro en el momento de la comunicación. Y esto vale también para la comunicación escrita.

Las relaciones socio-culturales del autor/emisor y del receptor/destinatario se refleja en las enunciaciones del texto (ET), que, al ser especificadas, se traducen en la clase de discurso (TD), del que deriva el tipo de frase (TF), que puede ser monólogo o diálogo, así como el tipo de texto (TT) (performativo o narrativo).

También el significado del discurso está íntimamente relacionado con la misma emisión de la expresión-habla, porque «significado es todo lo que se comunica, se sugiere se evoca; lo que el hablante quiere comunicar y lo que el oyente entiende como comunicado» (Coseriu, 1973: 206). Ello quiere decir que la entonación con que transmitimos un mensaje juega un papel importante en su comprensión. Por ejemplo, el tono con que un padre de familia se dirige a su hijo para que lo deje trabajar y no moleste, difiere enormemente si lo hace por primera vez, que si se dirige a él por quinta. En este caso es posible que vaya acompañado de un bofetón, que el propio niño podría haber evitado, si hubiera estado atento a las llamadas de atención anteriores, que se han ido sucediendo en tono escalonado de impaciencia y enfado.

Por otra parte, la comprensión de un acto linguístico supone un saber mucho más amplio que el encerrado en los propios signos lingüísticos. Existen ciertos supuestos que arrancan de la capacidad de hablante y oyente de hacer inferencias a partir de las proposiciones explicitadas (Van Dijk-Kintsch, 1978: 64). Se trata de toda una serie de condiciones implícitas que hacen los emisores cuando quieren realizar un acto comunicativo eficaz y que poseen un enorme relieve textual: son las implicaturas y las presuposiciones ${ }^{8}$.

La implicatura es una dimensión pragmática del significado que genera inferencias, que van más allá del contenido semántico de las oraciones enunciadas. Se trata de un concepto esencial si queremos explicar adecuadamente distintos aspectos básicos del lenguaje. Las presuposiciones, por el contrario, forman

${ }^{7}$ Las ideas claves sobre el tema del principio de cooperación fueron propuestas por Grice en una conferencia que dictó en Harvard en 1967 y cuyas ideas fueron publicadas parcialmente en 1975. (Grice en Cole \& Morgan, 1975: 41-58).

\& Véase a este respecto: García Berrio, 1978: 61; Sánchez de Zavala, 1973: 0.4 y 0.9; 1976: 25 30; Kiparski, 1967-68: 31-36; Van Dijk, 1980: 293; Schmidt, 1973: 105; Leech, 1977: 321-356; Ducrot, 1972, cap. 2; Albaladejo-García Berrio, 1983: nota 33. 
parte del significado convencional de las expresiones (Levinson, 1989: 89-157 y 158-215; Reyes, 1990: 62-88).

El lenguaje -como señala Victoria Camps - no puede escapar a una serie de costumbres y hábitos que no pueden ser violados, sino con el riesgo de que las palabras se vuelvan incomprensibles (1976: 126).

Porque el lenguaje refleja también el lado positivo de la vida, la necesidad perpetua de realizar un fin, cuenta con un rasgo que es su carácter activo, es decir, esa tendencia que impulsa a la palabra a servir a la acción (Bally, 1977: 23-28). De ahí que el uso que del lenguaje hacen los hablantes engendra una serie de actos lingüísticos o actos de habla (Austin, 1971: 41-42; 1975: 217 231; Searle, 1980: 25-28). Hablar un lenguaje es ejecutar actos de habla, tales como hacer afirmaciones, dar ordenes, hacer preguntas, etc. es decir, al emitir una expresión realizo una acción o acto ilocucionario (Van Dijk, 1980: 278279). La adecuación de los actos realizativos arranca de una serie de condiciones que parten del contexto comunicativo y que son los postulados conversatorios que subyacen a las estructuras mentales de hablantes y oyentes (Gordon-Lakoff, 371-401; Lakoff, 1971: 403-435). Un hablante que desee mantener un discurso coherente debe contar además con un «plan disponible» para la organización semántica y pragmática global del discurso (Van Dijk, 1980: 234), lo que implica que los actos de habla han sido cuidadosamente planificados.

En la elaboración de la información, y también en su recepción, el hablante crea un relato que contiene principalmente macro-proposiciones y lo que comunica es un macro-acto de expresión, en torno al cual se organiza toda la información. El macro-acto de expresión es una hipótesis pendiente de confirmación, al que hay que asociarle toda una serie de actos de habla, cuya ordenación dependerá del contexto comunicativo. A partir de aquí habrá que seleccionar adecuadamente la estrategia narrativa, en la que la implicatura y la presuposición desempeñarán un papel relevante.

Por otra parte, el proceso seguido por el lector/oyente para comprender la información, le ha llevado a utilizar un mecanismo que está basado fundamentalmente en la intuición y en la propia habilidad de resumir (Hendricks, 1976: 209-229; Greimas, 1976: 224ss.) y que tiene que ver con lo que Bühler denomina «principio de relevancia abstractiva» (1979: 48).

De esta forma, y a partir del macro-acto de expresión, se puede llegar a la generación del texto, que confirmará la hipótesis inicial construida por el lector.

8.3. En la investigación textual el descubrimiento de indicios que remiten a sistemas culturales externos, así como el estudio de todos los aspectos extratextuales, es sumamente pertinente para la interpretación completa del mensaje. Así, por ejemplo, en absoluto es indiferente para la comunicación el que el autor de los Milagros de Nuestra Señora sea clérigo, pues esta realidad da lugar a un tipo de relaciones entre emisor y destinatarios del mensaje, que condiciona el objetivo del mismo y justificándose así toda una serie de consejos que circulan a lo largo de la obra, así como el recorrido argumental de cada uno de los relatos de la colección berceana, hecho que guarda perfecta coherencia con 
la época en que se produce la obra. Igualmente el descubrimiento de la identidad de los posibles destinatarios, peregrinos creyentes, explicaría el lenguaje «sermonario» del poeta de San Millán de la Cogolla (Albert, 1987: 182-234).

«Se ha olvidado con demasiada frecuencia que el contexto más evidente y activo en la formación de los textos artísticos es el literario». Estas palabras fueron escritas por García Berrio en 1978 (p. 243) al referirse a las tareas de mayor urgencia de la Lingüistica Textual, reivindicando así la necesidad de abordar las reglas de integración de cada texto dentro de su clase, para definirlo dentro de la tradición literaria, aunque no debe olvidarse que la interpretación es siempre aproximativa, pues el modelo artístico es más amplio y más vivo que su interpretación (Lotman, 1978). La obra de arte, y cualquier otro texto, deberá abrirse a todo aquello que, de alguna manera, incida en el propio texto, apoyándose en una visión lo más amplia posible, a partir de la cual podrá llegarse a determinados descubrimientos que, al no poseer una visión de conjunto, serían ignorados por los investigadores. Por ejemplo, la presencia de los símbolos de la naturaleza, como es la fuente, el árbol, las flores, etc. en la «Introducción» a los Milagros de Berceo, tiene su significación exclusivamente en la tradición literaria. Es patrimonio de una larga cadena que arranca de La lliada y de La Odisea (Curtius, 1976: 263ss.).

Por otra parte, la renovación actual de la Retórica, sobre todo el establecimiento de una nueva INVENTIO, que atienda al desarrollo doctrinal de una teoría pragmática de la influencia o la persuasión, puede suponer una aportación inestimable en la interpretación de textos (Pozuelo, 1987: 181-211; García Berrio, 1984; García Berrio-Albaladejo, 1989). Es de sobra conocido que la antigua retórica fue un metalenguaje que funcionó como un «arte» dirigido a conseguir un único objetivo: convencer al destinatario del discurso.

Las dos grandes líneas que parten de la INVENTIO, convencer y emocionar, requieren respectivamente un aparato lógico cuyas pruebas, por su propia fuerza, ejerzan una violencia justa, mediante el razonamiento sobre el espíritu del oyente y en pensar el mensaje probatorio según el espíritu de quien debe recibirlo. Se trata de toda una serie de procedimientos que prueban la eficacia de un autor, contagiando al público/lector de su sistema de valores, planteado como un proceso de persuasión mediante la palabra («verba») y su organización («dispositio») para seducir al auditorio («captatio benevolentiae»). La DisPositio se ha invocado precisamente como antecedente de las gramáticas textuales (Albert, 1990: 109-118).

La investigación del texto debe descubrir además cómo la posición de una obra cambia con la aparición de otras nuevas y explicar por qué existen y cuáles son las presuposiciones extraliterarias, históricas y culturales que, de alguna manera, preparan el camino, no sólo para cierta comprensión de la obra y su consideración, sino incluso para justificar parte de su existencia. En este sentido el texto se manifiesta también como signo en su relación con la sociedad de la que emerge en un momento determinado de la historia de la cultura. Las coordenadas espacio-temporales, por ejemplo, pueden explicar el 
empleo de determinadas figuras retóricas e imágenes literarias. Determinadas comparaciones que aparecen en un texto son inimaginables unos siglos después, como es el caso de la obra de Gonzalo de Berceo, donde el texto siguiente: «fue de sancta María vassallo e amigo» (Copla 276d, Ed. Dutton) encuentra únicamente su explicación en la época en que fue creada (siglo XIII). La sociedad de entonces estaba profundamente marcada por lo que Sánchez Albornoz denomina «religiosidad vasallática» (1973: 329-358).

9. El diagrama siguiente quiere ser reflejo del estudio realizado de los componentes de la comunicación textual, así como de su ensamblaje. El resultado es la generación del texto, objeto de la comunicación:

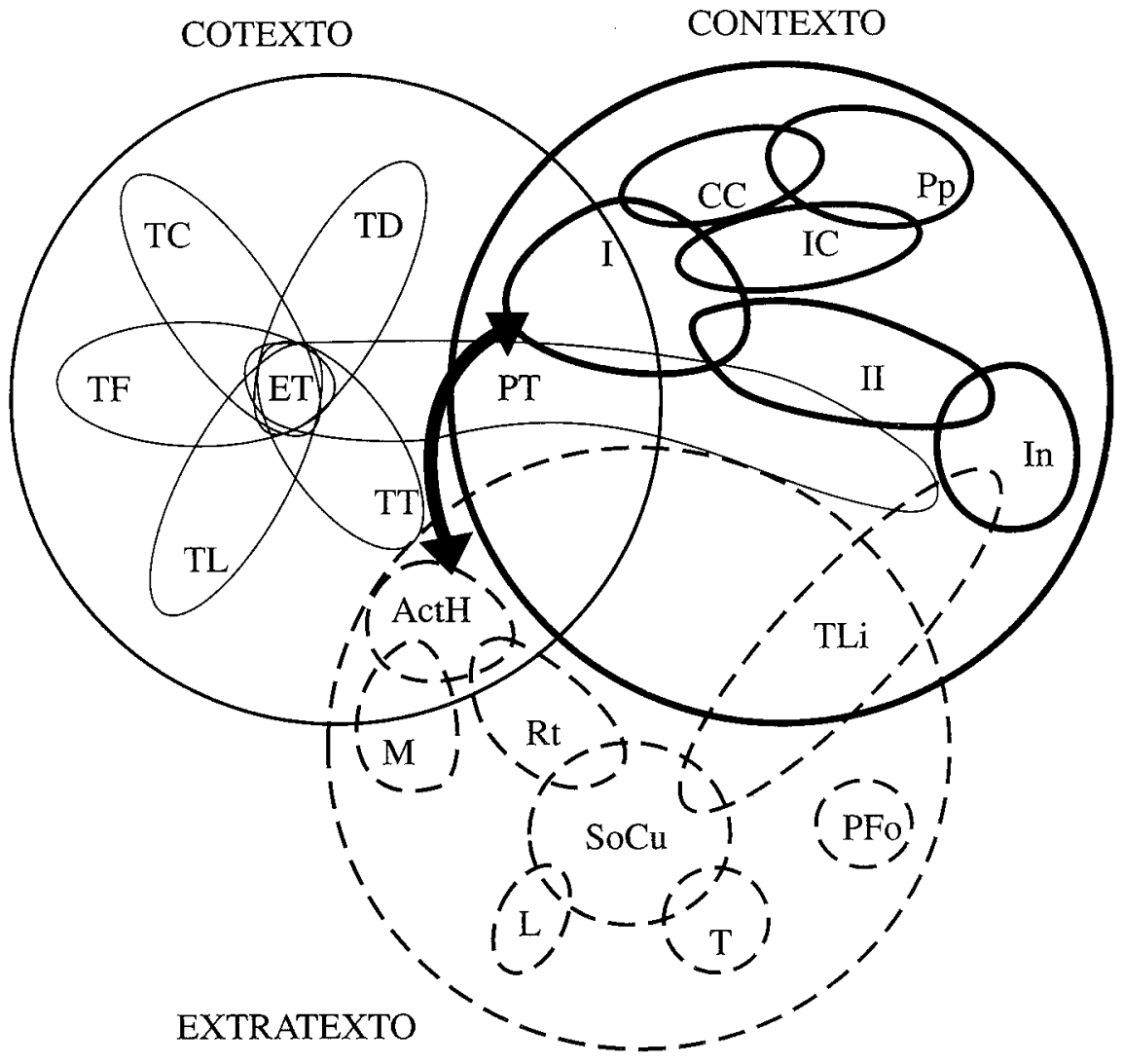


Act. $\mathrm{H}=$ actos de habla

$\mathrm{CC}=$ competencia comunicativa

$\mathrm{ET}=$ enunciaciones del texto

$\mathrm{I}=$ interlocutores

ICE = intención de realizar una comunicación eficaz

II $=$ identidad de los interlocutores

In $=$ indicios

$\mathrm{L}=$ lugar

$\mathrm{M}=$ marco

Pfo = parámetros fónicos

$\mathrm{Pp}=$ presuposiciones $\mathrm{y} / \mathrm{o}$ implicaturas

$\mathrm{Rt}=$ retórica

SoCu $=$ parámetros socio-culturales

$\mathrm{T}=$ época

$\mathrm{TD}=$ tipo de discurso (profano/religioso)

$\mathrm{TF}=$ tipo de frase (exhortativa, interrogativa, etc.)

$\mathrm{TL}=$ tipo de locución (directa/indirecta)

$\mathrm{TLi}=$ tradición literaria

TO = tipo de oración (monólogo/diálogo)

$\mathrm{TT}=$ tipo de texto (performativo/narrativo).

9.1. Las siglas que aparecen encerradas en el primero de los círculos (trazo continuo normal) expresan la materia con la que trabajamos, la superficie del texto, el enunciado concreto. Los interlocutores (I) en el mismo círculo y compartiendo su espacio con los actos de habla (Act.H) (flecha de doble punta), tiene su justificación en el hecho de que la presencia explícita del «yo» y del «tú» (obviamente en el caso de que exista) da fuerza persuasoria al decir del autor; se plasma en los actos de habla. No se olvide que los factores pragmáticos van estrechamente unidos a la manifestación textual y afectan a las relaciones y alcance de los constituyentes del mismo, posibilitando y documentando el dominio de las circunstancias verbales en el círculo cotexTo, que comparte con los otros dos, es decir, contexto y EXTRATEXTo, respectivamente.

La presencia del «yo» y del «tú» en el cotexto alcanza su interpretación en el contexto (trazo grueso) donde adquiere carácter persuasorio, obligando a adoptar una determinada estrategia de planificación de los actos de habla. Tiene su fundamento en la RETóRICA CLÁsICA y, como es visible, procede del ámbito extratextual (trazo discontinuo).

En el círculo del cotexto aparece PT, que abarca, por un lado y en el recinto cotextual, a I, saliendo fuera de su campo para introducirse en el contexto. Los parámetros textuales, al referirse a todos aquellos aspectos que explícitamente aparecen en la manifestación textual, como es el caso de I, II, ET, lógicamente ocupa el cotexto y el contexto.

Por otra parte, I comparte su «mundo espacial» con CC y con ICE, debido a que estos dos componentes forman parte de las inferencias (implicaturas y presuposiciones) que se pueden hacer a partir de un texto concreto: su 
interpretación alcanza sentido en el contexto. La $\mathbf{C C}$ tiene que ver con el conocimiento común de una lengua, que es base del entendimiento de un «yo» con un «tú»o, lo que es lo mismo, es lo que posibilita la comunicación lingüística. Siempre que existe comunicación se presupone la intención de realizarla y, por lo tanto, de que sea eficaz al acto de traspasar un emisor a un receptor unos contenidos encerrados en signos lingüísticos (ICE). Tanto $\mathbf{C C}$ como ICE forman parte de las presuposiciones de todo acto de habla.

La presencia de II, que arranca de In, se refiere a todas aquellas señales que remiten a sistemas culturales externos. Tiene que ver con la investigación que debe llevarse a cabo sobre la identidad de los intervinientes (flecha de trazo discontinuo) en la comunicación. Esa es la razón de que figure en el recinto de trazado normal o cotexto. Obsérvese que TLi arranca también de In, aunque se extiende hasta el círculo del extratexto (trazo discontinuo), debido a que pertenece a una realidad exterior al texto, aunque obviamente incida en él: es indicador de los antecedentes literarios. Su conexión con PT se explica porque están presentes en el enunciado algunos elementos de la naturaleza, presencia, por otra parte, que arranca de la tradición del «locus amoenus», por ejemplo.

En el extratexto aparece como elemento central $\mathbf{S o C u}$, del que parten todos aquellos componentes que tienen que ver con los aspectos socio-culturales, lo que explica su situación. Por un lado, tiene que ver con el conocimiento del mundo $y$, por otro, con todo lo que está fuera del texto, pero que tiene incidencia en él. Uno de sus componentes es $\mathbf{T L i}$, ya visto. Otro es $\mathbf{M}$, cuyo conocimiento influirá de manera decisiva en la planificación de los actos de habla y en la estrategia a seguir. El lugar y la época ( $\mathbf{L}$ y $\mathbf{T}$ ) son los últimos componentes que conectan con el SoCu.

Los parámetros fónicos (PFo) aparecen «descolgados» de cualquier otro componente a causa de que se trata de un elemento, que sólo figura en textos de que han sido creados expresamente para ser dichos, como es el caso de las obras de teatro, o que sirven de base para una charla, una conferencia, un sermón, etc.

En el diagrama no figuran los componentes de «coherencia lineal»y «coherencia global», así como el del léxico. Se trata de componentes procesuales generales que intervienen regulando toda esa compleja red de relaciones, cuyos hilos penetran en el tejido de la lengua y la traspasan para presentarla como una producción transparente, en cuyas aguas el lingüista intenta, entre brazada y brazada, penetrar en sus profundidades para arrancarle el secreto de su transparencia, de su organización, que por todo ello la hacen apta para la comunicación entre los humanos.

10. Todas las definiciones de los componentes deben ser recogidas en reglas $(\mathbf{R})$, donde $\mathbf{R}$ significa: «considere la relación entre los contenidos de los paréntesis» (paréntesis y corchetes especifican):

TEXTO $\rightarrow$ ET (TD, TL, TF, TO, TT) + I (CC, ICE, II) + SoCu

$(\mathbf{T L i}, \mathbf{T}, \mathbf{L})+$ Act.H + PFo), que debe leerse: 
El TEXTO se define como la RELACIÓN entre las ENUNCIACIONES DEL TEXTO, los INTERLOCUTORES, los parámetros SOCIO-CULTURALES, los ACTOS DE HABLA y IOS PARÁMETROS FÓNICOS.

\section{Referencias bibliográficas}

ALBALADEJO MAYORDOMO, T. (1981), «Aspectos del análisis formal de textos», Revista Española de Lingüística, n. 11, Madrid, Gredos.

ALBALADEJO MAYORDOMO, T. (1983), «Componente pragmático, componente de representación y modelo lingüístico-textual», Lingua e Stile, XVII, n. 1, gennaio-marzo.

ALBALADEJO MAYORDOMO, T. y GARCíA BERRIO, A. (1983), «La lingüística del texto», Introducción a la lingüistica, Madrid, Alhambra.

ALBERT GALERA, J. (1987), «Reflexiones metodológicas», Estructura funcional de los «Milagros» de Berceo, Logroño, Instituto de Estudios Riojanos,9-12.

ALBERT GALERA, J. (1989), «Semiosis textual y superposición de mundos», Actas IV Congreso de la International Association for Semiotic Studies (Barcelona-Perpignan), Abril, 1989. (En prensa).

ALBERT GALERA, J. (1990), «Retórica del personaje y sentido», Investigaciones Semióticas. III, Madrid, UNED, 109-118.

AUSTIN, J. (1971), «Conferencia I», Palabras y acciones. Cómo hacer cosas con palabras, Buenos Aires, Paidós, 41-42.

AUSTIN, J. (1975), «Emisiones realizativas», Ensayos filosóficos, Madrid, Revista de Occidente, 217-231.

BAJTÍN, M. (1982), Estética de la comunicción verbal, México, Siglo XXI.

BALLY, Ch. (1977), El lenguaje y la vida, Buenos Aires, Losada, $7^{\mathrm{a}}$ Edic.

BOBES NAVES, $M^{a}$ C. (1989), La semiologia, Madrid, Síntesis, n. 12.

BÜHLER, K. (1979), Teoría del lenguaje, Madrid, Alianza Editorial.

BUSTOS, E. (1976), Pragmática del español, Madrid, UNED.

BREKLE, H. E. (1974), Sémantique, Paris, Armand Colin.

CAMPS, V. (1976), «El lenguaje de la fe», Pragmática del lenguaje y filosofía analítica, Barcelona, Península.

COSERIU, E. (1973), Teoría del lenguaje y lingüística general, Madrid, Gredos, $3^{\mathrm{a}}$ Edic. revisada y corregida.

CURTIUS, E. R. (1976), Literatura europea y Edad Media latina (I), Madrid, F.C.E.

VAN DIJK, T. A. (1980), Texto y contexto. Semántica y pragmática del discurso, Madrid, Cátedra.

VAN DIJK, T. A. (1983), «Introducción», La ciencia del texto, Barcelona-Buenos Aires, Paidós-Comunicación.

VAN DIJK, T. A. y KINTSCH, W. (1978), «Cognitive psichology and Discourse: Recalling and Summarizing Stories», Trends in Textlinguistics, Berlin, New York, Edited by Wolfgang U. Dressler, Walter de Gruyter. 
DUCROT, O. (1972), Dire et ne pas dire. Principes de Sémantique linguistique, Paris, Herman.

GARCÍA BERRIO, A. (1978), «Situación de la teoría textual», PETÖFIGARCÍA BERRIO, Lingüística del texto y crítica literaria, Madrid, Comunicación, 53-98.

GARCÍA BERRIO, A. (1979), «Lingüística, literariedad/poeticidad (gramática, pragmática, texto)», Sociedad Española de Literatura General y Comparada, Anuario II.

GARCÍA BERRIO, A. (1984), «Retórica como ciencia de la expresividad (presupuestos para una Retórica General)», Estudios de Lingüística, n. 2, Universidad de Alicante.

GARCÍA BERRIO, A. y ALBALADEJO MAYORDOMO, T. (1983), «Estructura composi-cional. Macroestructuras», Estudios de Lingüística, n. 1, Universidad de Alicante, 127-179.

GARCÍA BERRIO, A. y ALBALADEJO MAYORDOMO, T., Retórica, Madrid, Síntesis.

GORDON, D. y LAKOFF, G. (1971), «Losa postulados conversatorios», AA.VV., Semántica y sintaxis en la lingüística transformatoria/2, Madrid, Alianza Editorial.

GREIMAS, A. J. (1976), Semántica estructura. Investigación metodológica, Madrid, Gredos.

GREIMAS, A. J.-COURTÉS, J. (1982), Semiótica. Diccionario razonado de la teoría del lenguaje, Madrid, Gredos.

GRICE, H. P. (1975), «Logic and conversation», Cole, P. \& Morgan, J. L. (Comps.) (1987), Syntax and Semantics 3: Speech Acts, New York, Academic Press, 41-58.

HENDRICKS, W. O. (1976), Semiología del discurso literario, Madrid, Cátedra. HJELMSLEV, L. (1974), Prolegómenos a una teoría del lenguaje, Madrid, Gredos.

KRISTEVA, J. (1978), «El engendramiento de la fórmula», Semiótica 2, Madrid, Espiral/Fundamentos, 95-217.

KIPARSKI, P. Y C. (1967-1968), «Hechos», AA.VV., Semántica y sintaxis en la lingüística transformatoria/2, Madrid, Alianza Editorial, 31-36.

LAKOFF, R. T. (1971), «El lenguaje en su entorno», AA.VV., Semántica y sintaxis en la lingüística transformatoria, Madrid, Alianza Editorial, 209-229.

LEECH, G. (1977), «Presuposiciones y facticidad», Semántica, Madrid, Alianza Editorial, 321-356.

LEVINSON, S. (1989), Pragmática, Barcelona, Teide.

LOTMAN, Y. M. (1978), Estructura del texto artístico, Madrid, Fundamentos/ Itsmo.

LYONS, J. (1983), Lenguaje, significado y contexto, Barcelona, PaidósComunicación, 16.

MORRIS, Ch. (1958), Fundamentos de la teoría de los signos, México, Universidad Autónoma de México, Seminario de problemas científicos y filosóficos. 
MORRIS, Ch. (1962), Signos, lenguaje y conducta, Buenos Aires, Losada.

OLLER, I. W. (1972): «On the relation between syntax, semantics, and pragmatics», Linguistics, 83, Mayo, pp: 43-55.

PETÖFI, J. S. (1975), Vers une théorie partielle du texte, Papeiere zur textlinguistik, Helmut Buske Verlag, Hamburg.

PORZIG, W. (1974), El mundo maravilloso del lenguaje. Problemas, métodos y resutlados de la lingüística moderna, Madrid, Gredos.

POZUELO YVANCOS, J. M. (1987), Del formalismo a la neorretórica, Madrid, Taurus.

RAMÓN TRIVES, E. R. (1979), Aspectos de semántica lingüístico-textual, Madrid, Alcalá/ltsmo.

RAMÓN TRIVES, E. R. (1980), «Nuestro hablar: proceso pragmáticamente no exento», Monteagudo, 68.

REYES, G. (1990), La pragmática lingüística (el estudio del uso del lenguaje), Barcelona, Edit. Montesinos.

RIESER, H. (1978), «INTRODUCCIÓN. El desarrollo de la gramática textual», Petöfi-García Berrio, Lingüística del texto y crítica literaria, Madrid, Comunicación.

ROBINS, R. H. (1976), Lingüística general. Estudio introductorio, Madrid, Gredos.

SÁNCHEZ DE ZAVALA, V. (1973), Indagaciones praxiológicas. Sobre la actividad lingüística, Madrid, Siglo XXI.

SÁNCHEZ DE ZAVALA, V. (1976), «Las presuposiciones», AA.VV., Semántica y sintaxis en la lingüística transformatoria, 2, Madrid, Alianza Editorial, 25-30.

SAUSSURE, F. de (1976), Curso de lingüística general, publicado por Charles Bally y Albert Sechehaye, Buenos Aires, Losada, $15^{\mathrm{a}}$ Edic.

SEARLE, J. (1980), «¿Por qué estudiar actos de habla?», Actos de habla, Madrid, Cátedra, 25-28.

WEINRICH, H. (1981), Lenguaje en textos, Madrid, Gredos. 